\title{
Theoretical Modeling of Power Cycles Using an Interactive Computational Tool
}

\author{
Natalia Duarte Forero, Guillermo Valencia Ochoa ${ }^{*}$, Donoban Arango Barrios \\ Grupo de investigación en Gestión Eficiente de la Energía - Kaí, \\ Faculty of engineering, Universidad Del Atlántico, km 7 antigua vía Puerto, Barranquilla, Colombia \\ guillermoevalencia@mail.uniatlantico.edu.co
}

\begin{abstract}
One of the areas of greatest interest in engineering is the conversion of heat into useful work because society consumes large amounts of energy. In this paper, a theoretical study of the simple Rankine cycle, regenerative and cogeneration is presented, to verify the set of operational parameters that allow maximizing the output power of a power generation facility. For the theoretical modeling, the Powercycle ${ }^{\circledR}$ software was used, which can predict the output conditions of a Rankine power cycle depending on the configuration, input values and pressure in the boiler. With the purpose to verify the results obtained with regeneration and cogeneration, a comparison was made of the results obtained with a simple Rankine cycle. It was determined that, with the increase of the temperature and the pressure at the entrance of the turbine, the efficiency of the cycles increases. Note that an increase in temperature means more heat entering the process, but the delta of work in this case is greater, while it was verified that the Powercycle ${ }^{\circledR}$ computational tool allows optimizing the performance of Rankine cycles under different operating configurations.
\end{abstract}

Keywords - Cycle, Efficiency, Model, Rankine, Simulation

\section{INTRODUCTION}

A power cycle is a thermodynamic cycle in which heat is converted into work. There are different types of cycles depending on the working fluid, heat transfer mode and operational variables. In the case of steam power cycles, the working fluid is water, which changes from liquid phase to vapor phase depending on the analysis point in the installation. The continuous improvement of power generating systems has led to some innovative modifications in the Rankine basic power cycle [1]-[2]-[3], in order to increase the thermal efficiency of power generating systems[4]-[5]-[6].

In recent years these improvements have been focused on different fronts. Recently, many studies have focused on the application of the Rankine cycle (RC) to recover low quality waste heat. According to Zhou On-road vehicles, which convert about a third of the fuel energy into mechanical energy useful for propulsion, are moving energy conversion systems that generate considerable waste heat. This paper identifies the characteristics of the waste heat sources found in vehicles and the restrictions placed on the automotive RC application. Rankine's cycle architectures, system components and working fluids suitable for different applications are summarized, providing guidance for the future design of the RC system in automobiles[7].

Hofmann and Tsatsaronis describes an analysis of a binary and a conventional Rankine cycle for a coal-fired power plant. The main question asked in this research is whether it is possible to compensate the higher expected capital investment associated with additional components for lower fuel consumption during operation. The exergoeconomic comparative analysis shows that the concept of a binary Rankine cycle is suitable for reducing fuel and emissions and economically viable[8].

The Rankine cycle is considered the most common and competitive power generation cycle for producing electricity from solar thermal energy. For this reason Aboelwafa reviews the work done on Rankine's solar cycle power generation systems and focuses on the working fluids investigated in the literature and the application of these systems in water pumping and water desalination[9].

Anvari propose a combined cooling, heating and power cycle consisting of three sections of gas turbine and heat recovery steam generator cycle, regenerative Rankine cycle and absorption cooling cycle. This trigeneration cycle was subjected to an exhaustive thermodynamic and exero-economic analysis. The results indicate that adding regenerative Rankine cycle to gas turbine and heat recovery steam generator cycle leads to a $2.5 \%$ increase and adding absorption cooling cycle to the gas turbine and to the regenerative Rankine heat recovery steam generator/cycle would cause a $0.75 \%$ increase in the exergistic efficiency of the entire cycle[10]. 
Zebian and Mitsospresented a double-pronged approach for closed feedwater heaters (FWH) from regenerative Rankine cycles. FWHs are modeled as countercurrent heat exchangers. Therefore, there are two possible Pinch positions in the FWH: (i) at the drain outlet and (ii) at the start of condensation. The criteria is shown numerically for the fixed Pinch value and for the area of the fixed heat exchanger using the most common configurations: drain to the condenser, drain to the deaerator and cascade to the next FWH. For numerical reasons, the authors recommend using pressure as the optimization variable and calculating the mass flow rate[11].

$\mathrm{Fu}$ show the integration of process heat with the Rankine regenerative steam cycles by preheating the boiler feedwater to increase the power generation of the steam turbines. This work investigates the optimal integration of the air compression train in a cryogenic air separation unit with the regenerative steam cycle in an oxyfuel coal-based power plant using MINLP (mixed non-linear mixed scheduling). Two special cases (adiabatic compression and "isothermal" compression) were also investigated for comparison with the optimization results. The study shows that such heat integration increases the thermal efficiency of the reference power plant by a maximum of $0.5-0.6$ percentage points. The heat integration is less attractive when the temperature difference of the heat transfer between the compressed gas and the boiler feed water is greater than $40^{\circ} \mathrm{C}[12]$.

Sarr and Mathieu-Potvin propose three different modifications of the basic Rankine thermodynamic cycle. The aim is to increase the thermal efficiency of the energy systems according to the Rankine cycles. The three new systems are called"Rankine-1SCR","Rankine-2SCR" and"Rankine-3SCR" cycles, and consist of linking a cooling cycle with the basic Rankine cycle. The idea is to use the cooling cycle to create a low temperature heat sink for the Rankine cycle. Between 84 x 84 (i.e. 7056) possible combinations of working and cooling fluids were investigated in this work, concluding that: (i) the Rankine-1SCR system is advantageous for 1338 different fluid combinations, (ii) the Rankine-2SCR system is advantageous for 772 different fluid combinations, and (iii) the Rankine-3SCR system is advantageous for 768 different fluid combinations[13].

Mat Isa presents a comprehensive review of the cogeneration system, covering the main operation and types of primary motors available for use in the power plant, construction and industrial plant. Gas turbine, steam turbine, microturbine, alternative engine and fuel cell are compared in terms of size (kW), efficiency and main operation. This review also describes the hierarchical control system for the cogeneration system; classified into three types, which are local, centralized[14].

Zhang is investigating a Rankine cycle heat recovery cogeneration system with heat recovery and power generation to relieve grid load and save energy costs for a ferrochrome smelting plant. By recovering and using the heat previously wasted from the waste gases from the internal smelting process of the facility, the cogeneration system is introduced to generate electricity to supply the demand for electricity on site and feed back into the grid when necessary and beneficial. The heat recovery process for power generation is modeled and the optimal dispatch of energy between the loads on site and the public grid is formulated as an economic power dispatch (EPD) problem, which seeks to maximize the economic benefits of the plant by minimizing the cost of purchasing electricity from the company and maximizing the revenue from selling the generated electricity to the grid[15].

Considering the previous contextualization, a theoretical study of the ideal simple, regenerative and cogenerative Rankine cycle using Powercycle ${ }^{\circledR}$ software was carried out in this work, in order to verify the set of operational parameters that influence the output power of a power generation installation.

\section{METHODOLOGY}

Powercycle ${ }^{\circledR}$ is a Matlab application which was developed to provide a useful tool for mechanical engineering students and areas for purposes; this program offers a high level of interactivity thanks to its easy use and its environment designed to encourage self-learning through multiple case studies focused on the analysis of the relationship between the main parameters of the power cycles, among which is the simple Rankine cycle, such as.

This program allows you to see quickly and clearly with the help of the T-s diagram how varying the power cycle settings can lead to efficiency improvements. Similarly, varying certain thermodynamic properties (T, P, $\mathrm{x}$ ) in a given cycle can improve efficiency or negatively influence it. In order to verify the predictive capacity of the Powercycle ${ }^{\circledR}$ software tool, which has a theoretical model for predicting the behavior of different combinations of the Rankine cycle, an analysis of the variables that most influence the phenomenon was carried out, based on a complete review bibliography. Taking this as a starting point, a parametric analysis of the input variables of the model and their response is carried out, following the methodology described below. 


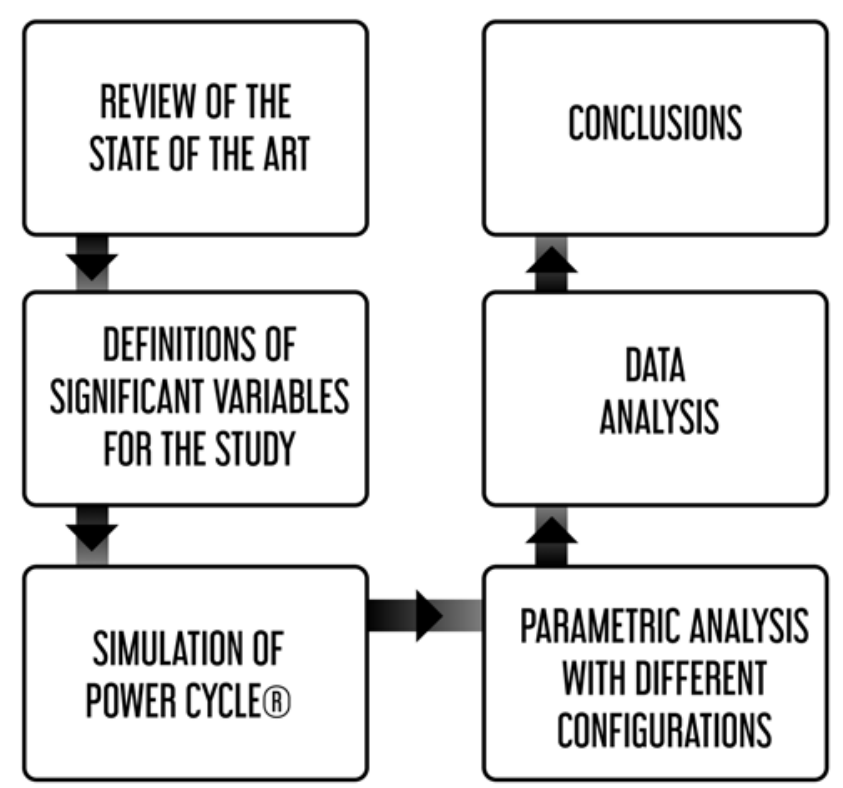

Fig. 1. Methodology for the study with the Powercycle ${ }^{\circledR}$ tool[16]

Figure 2 shows the Powercycle ${ }^{\circledR}$ initial screen, where the main menu with the different power cycle processes is detailed; Figure 3 shows the Rankine cycle to be implemented,where the user must enter the parameters associated with the phenomenon to be studied.

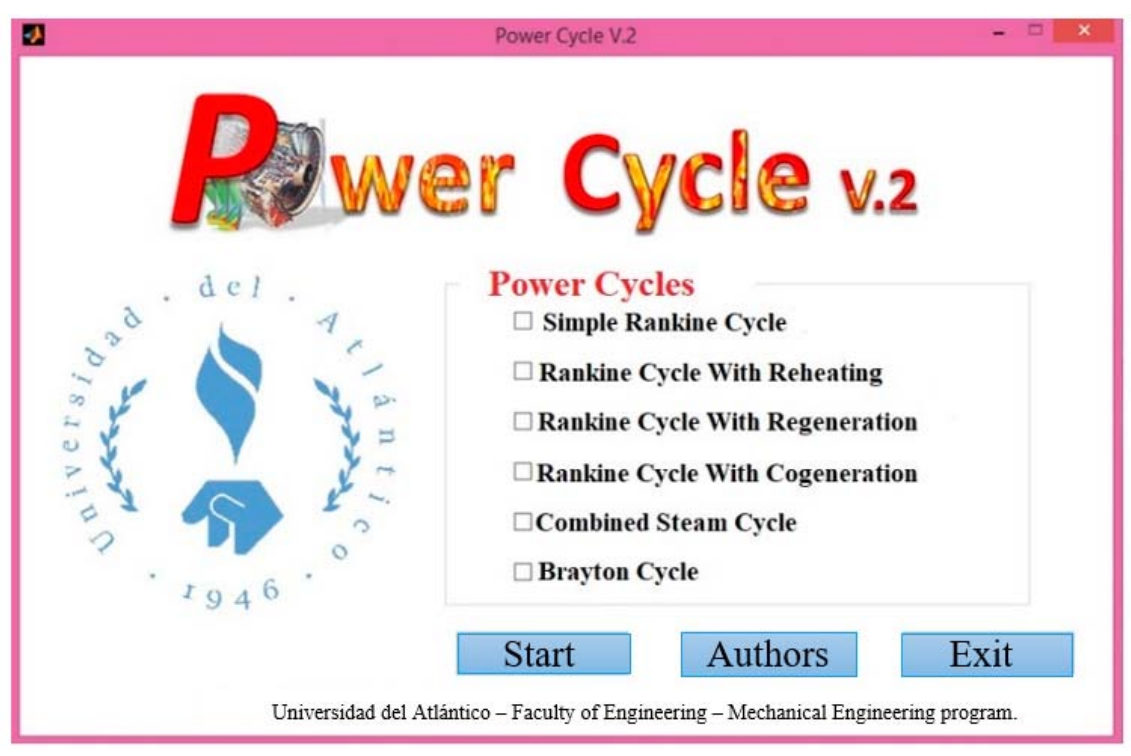

Fig. 2. Powercycle $®$ main menu window[16] 


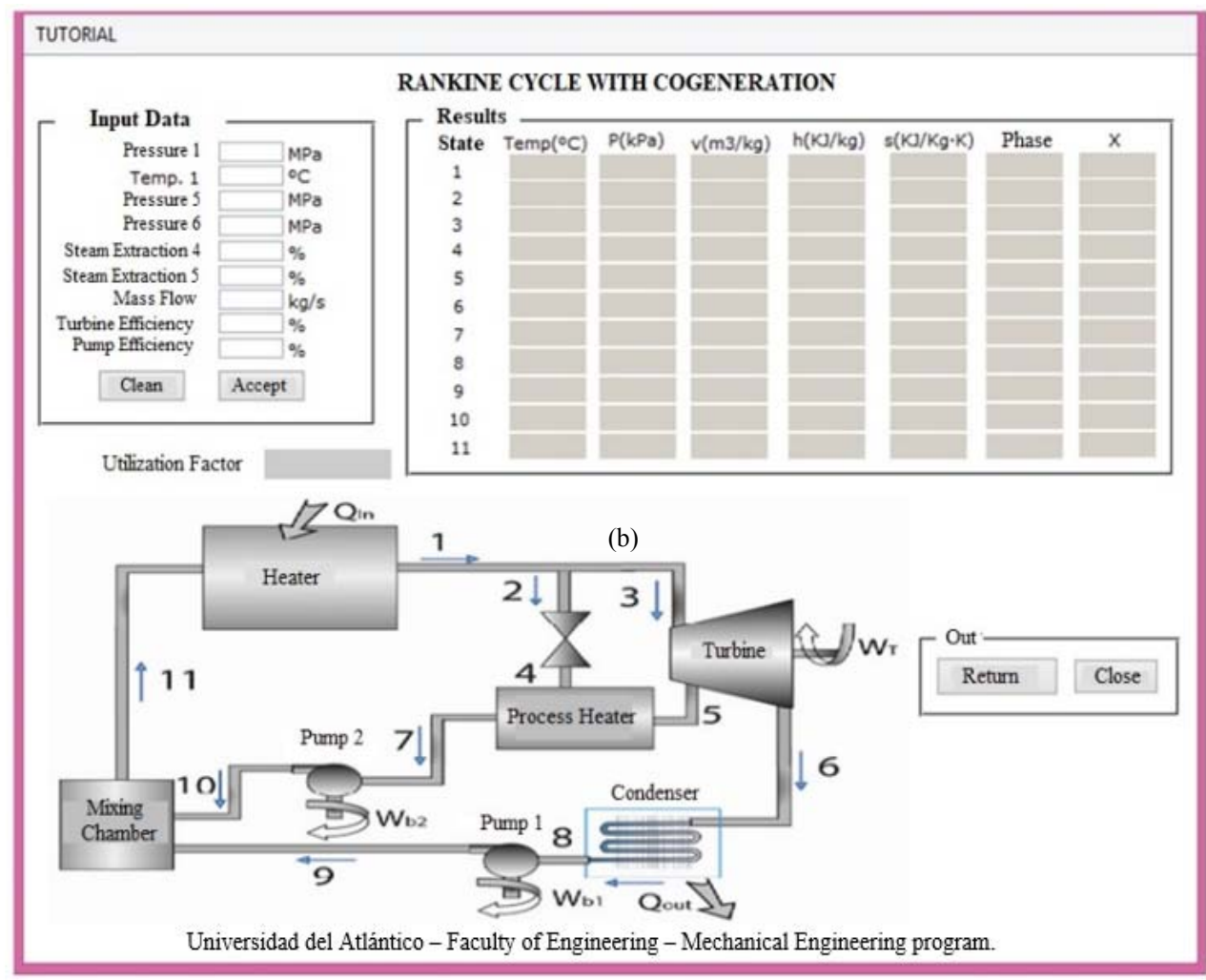

Fig. 3. Powercycle ${ }^{\circledR}$ main windows.Rankine simple cycle with cogeneration[16]

Powercycle ${ }^{\circledR}$ to solve the case studies has certain equations, which will be shown below.

A. Simple ideal Rankine cycle

The disadvantages of the Carnot cycle can be eliminated by replacing it with a simple Rankine cycle, consisting first of a constant pressure heating in a boiler, followed by isentropic expansion in a turbine, then cooling at constant pressure in a condenser and ending with isentropic compression in a pump.

The above components for the single Rankine cycle are then analyzed as a control volume in steady state:

$$
\begin{gathered}
\dot{Q}_{\text {neto }}-\dot{W}_{\text {neto }}=d E_{\text {sistem }} / d t \\
\dot{E}_{i}-\dot{E}_{e}=\frac{d E_{\text {sistem }}}{d t}=0 \\
\dot{E}_{i}=\dot{E}_{e}
\end{gathered}
$$

Compared to the work and heat transfer that occurs in the cycle, the changes in potential and kinetic energy are small, so they are not taken into account in the balance sheet. The turbine and pump are considered isentropic (no heat transfer), and the boiler and condenser do not perform or consume any work. Therefore, we are left with the energy and mass balance equation for each component that;

Work of the turbine, taking into account that the heat is zero:

$$
\mathrm{w}_{\text {turbine.output }}=\mathrm{h}_{1}-\mathrm{h}_{2}
$$

Pump work, taking into account that the heat is zero:

$$
\mathrm{w}_{\text {pump.inlet }}=\mathrm{h}_{4}-\mathrm{h}_{3}
$$

Heat of the condenser, taking into account that the work is zero:

$$
\mathrm{q}_{\text {condenser output }}=\mathrm{h}_{2}-\mathrm{h}_{3}
$$

Heat from the boiler, taking into account that the work is zero:

$$
\mathrm{q}_{\text {boiler.input.boiler }}=\mathrm{h}_{1}-\mathrm{h}_{4}
$$

Therefore, the thermal performance of the simple ideal Rankine cycle is expressed as follows:

$$
\eta_{\text {ter }}=\frac{\mathrm{w}_{\text {neto }}}{\mathrm{q}_{\text {input }}}=1-\frac{\mathrm{q}_{\text {output }}}{\mathrm{q}_{\text {input }}}
$$




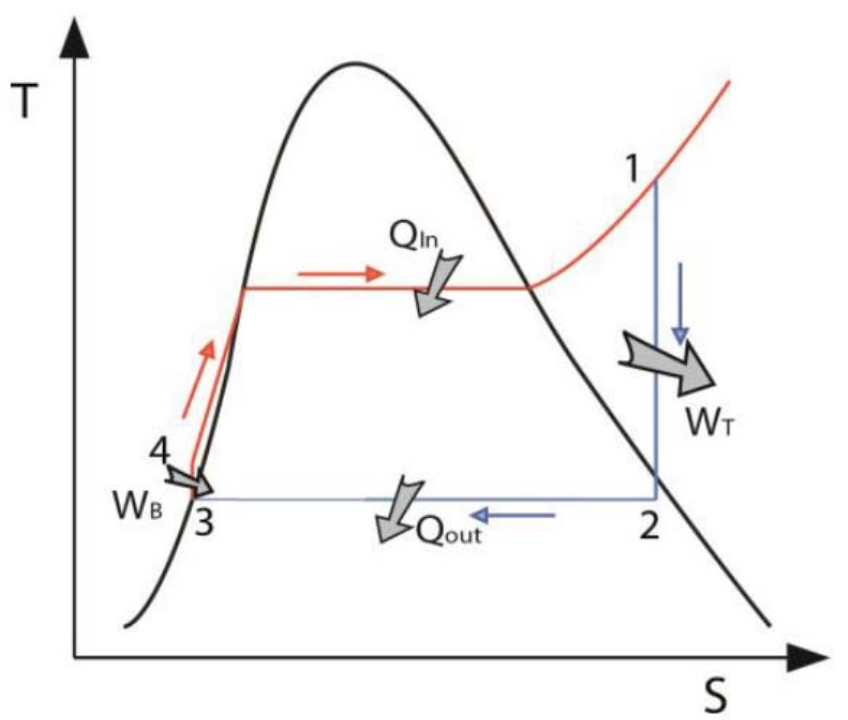

Fig. 4. T-s diagram and diagram for the simple Rankine cycle[16]

\section{B. Ideal regenerative Rankine cycle}

The continuous improvement of the power generating systems has produced some innovative modifications in the basic power cycle, in order to increase the thermal efficiency of the power generating systems. Among them is the cycle with regeneration or recovery, which seeks to reduce the amount of heat added to improve the efficiency of the cycle as the feed water is preheated using the expanded steam. The heat exchangers known as feed water heaters play an important role in this cycle, and are nothing more than a mixing chamber in which the steam extracted from the turbine is mixed with the feed water from the pump. Ideally, the fluid leaving the heater is saturated liquid at heater pressure.

Through the first law of thermodynamics, you have to:

$$
\begin{gathered}
q_{\text {input }}=q_{\text {boiler }}=\left(h_{1}-h_{7}\right) \\
q_{\text {input }}=q_{\text {condenser }}=(1-y)\left(h_{3}-h_{4}\right) \\
w_{\text {output }}=w_{\text {turbine }}=\left(h_{1}-h_{2}\right)+(1-y)\left(h_{2}-h_{3}\right) \\
w_{\text {input }}=w_{\text {pump } 1}+w_{\text {pump } 2}=(1-y)\left(h_{5}-h_{4}\right)+\left(h_{7}-h_{6}\right)
\end{gathered}
$$

Where $y=\frac{\dot{m}_{2}}{\dot{m}_{1}}$ is the fraction of steam extracted from the turbine in the first phase.

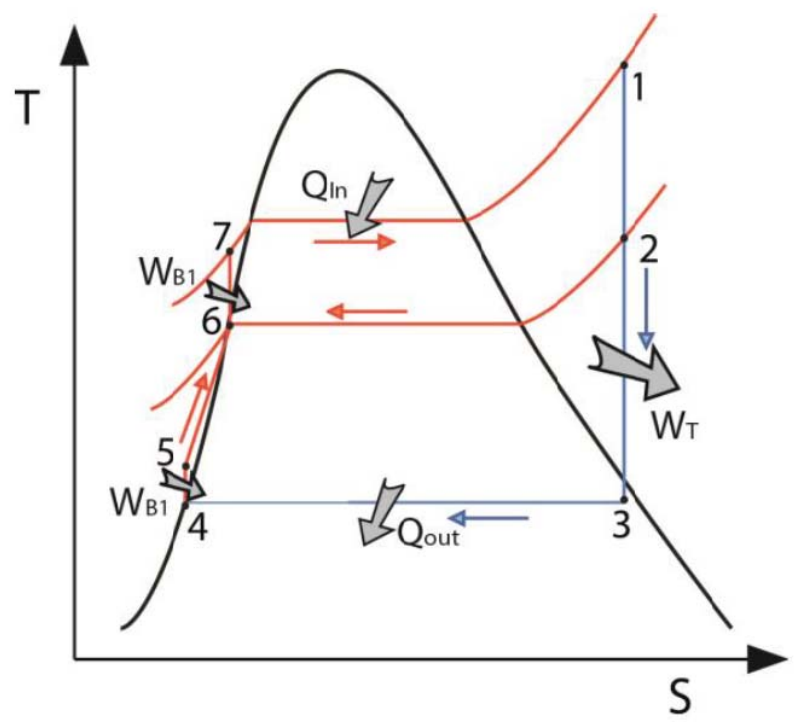

Fig. 5. Diagram and T-s diagram for the Rankine cycle with regeneration[16] 


\section{Ideal Rankine cycle with cogeneration}

In the two processes seen above the conversion of thermal energy into useful work is done, as not all the input heat is converted into work, it is discarded to thermal sinks when it leaves the condenser. This cycle is of great benefit since it uses a part of the thermal energy that is not converted into work to feed certain devices, which require this energy as input. This thermal energy used is called process heat.

In the ideal Rankine cycle with cogeneration, part of the steam is extracted from the turbine at a certain pressure, the rest of the steam expands to the condenser pressure and then heat is removed at constant pressure from the condenser. When a high heat demand is required for the process, all the steam will be sent to the process heater, so there is no heat removal in the condenser, so the waste heat is zero.

For a cogeneration plant the energy equations are expressed as:

$$
\begin{gathered}
\dot{Q}_{\text {input }}=\dot{Q}_{\text {boiler }}=\dot{m}_{11}\left(h_{1}-h_{11}\right) \\
\dot{Q}_{\text {output }}=\dot{Q}_{\text {condensador }}=\dot{m}_{6}\left(h_{6}-h_{8}\right) \\
\dot{W}_{\text {output }}=\dot{W}_{\text {turbine }}=\dot{m}_{3}\left(h_{3}-h_{5}\right)+\dot{m}_{6}\left(h_{5}-h_{6}\right)
\end{gathered}
$$

For a cogeneration plant, the utilization factor $\epsilon_{u}$ is defined, which is expressed as,

$$
\begin{gathered}
\epsilon_{u}=\frac{\text { Net } \text { work output }+ \text { Process heat delivered }}{\text { Total heat input }} \\
\epsilon_{u}=\frac{\dot{W}_{\text {neto }}+\dot{Q}_{p}}{\dot{Q}_{\text {inpout }}}
\end{gathered}
$$

\section{RESULTS AND ANALYSIS}

\section{A. CASE STUDY 1: Simple ideal Rankine cycle}

\begin{tabular}{|c|c|c|c|c|}
\hline $\mathbf{T 1}\left({ }^{\circ} \mathrm{C}\right)$ & P1 (MPa) & P2 (MPa) & 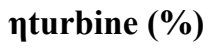 & 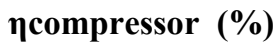 \\
\hline 300 & 4 & 0.08 & 100 & 100 \\
\hline
\end{tabular}

The effect of the temperature and steam pressure at the boiler outlet (T1 and P1, respectively) on the thermal efficiency of the cycle $(\eta)$ and the quality of the mixture at the turbine outlet (X2) is investigated in a simple ideal Rankine cycle. The initial conditions are shown in Table 1.

TABLE I. Initial Conditions for the Case Study 1

The efficiency and quality of the mixture was calculated by varying the temperature T1 in a range of 300 to 580 ${ }^{\circ} \mathrm{C}$, with increments of $35^{\circ} \mathrm{C}$ and pressures $\mathrm{P} 1$ of 4,6 and $8 \mathrm{MPa}$. The results obtained are shown in figure 6 .

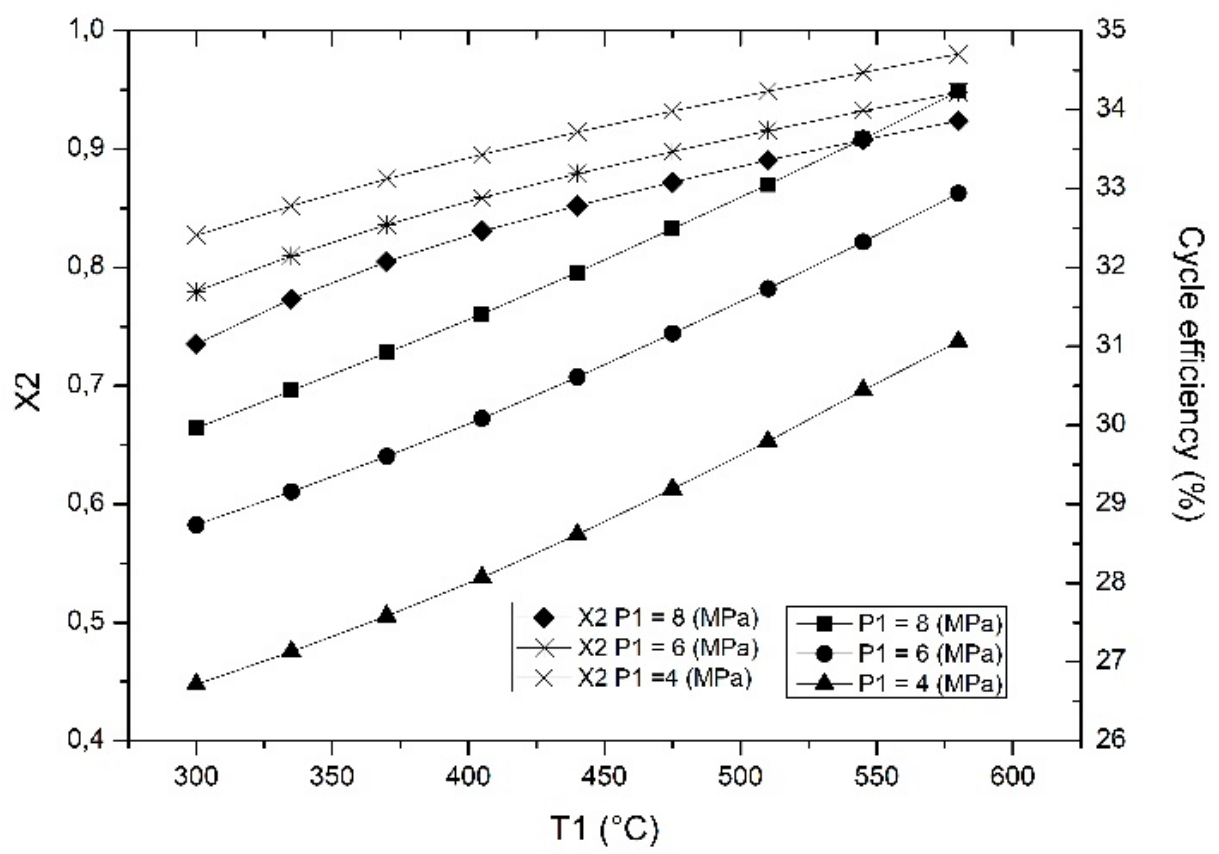

Fig. 6. Results of the case study of the simple ideal Rankine cycle[16] 
For a $280{ }^{\circ} \mathrm{C} \Delta \mathrm{T}$, the efficiency increased by $16.29 \%$ at a pressure of $4 \mathrm{MPa}$. As the pressure increases, efficiency is also positively influenced. Therefore, for a temperature of $580{ }^{\circ} \mathrm{C}$ and a pressure of $8 \mathrm{MPa}$ (maximum values for each range), the efficiency increased by $28.13 \%$ compared to the minimum data for each range. Now, the quality atthe turbine output increases with $\mathrm{T} 1$, but decreases with the increase of $\mathrm{P} 2$. Therefore, it should be noted that, under the conditions cited for this study, high efficiency could affect the life of the machine.

\section{B. CASE STUDY 2: Ideal Rankine cycle with regeneration}

In the ideal Rankine cycle with regeneration, the influence of the temperature variation (T1) at the boiler outlet on the efficiency $(\eta)$ and the working ratio $(\mathrm{rp}=\mathrm{Wb} / \mathrm{Wt})$ of the cycle was studied. In which the turbine bleeds at different pressures (P2). The initial conditions are shown in Table 2.

TABLE II. Initial conditions for case study 2

\begin{tabular}{|c|c|c|c|c|c|}
\hline $\mathrm{T} 1\left({ }^{\circ} \mathrm{C}\right)$ & P1 (MPa) & P2 (MPa) & P3 (MPa) & 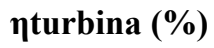 & $\eta \operatorname{compressor}(\%)$ \\
\hline 300 & 8 & 0.5 & 0.08 & 100 & 100 \\
\hline
\end{tabular}

Efficiency $(\eta)$ and working ratio $(r p=W b / W t)$ were calculated for different temperatures at the boiler outlet (T1) in a range of 300 to $580^{\circ} \mathrm{C}$, with increments of $35^{\circ} \mathrm{C}$. For turbine bleed pressures (P2) of $0.5,1,2$ and $3 \mathrm{MPa}$.

The results obtained are shown in figure 7.

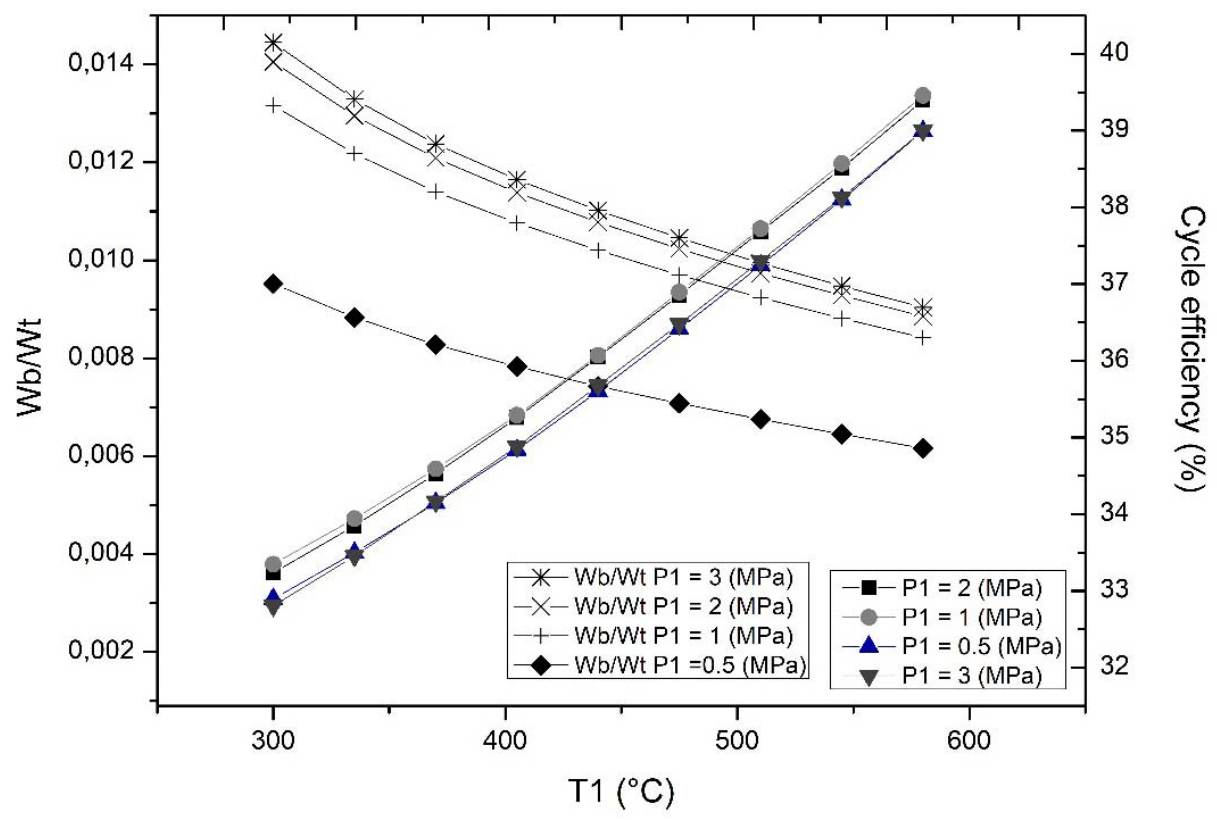

Fig. 7. Results of the case study of the ideal Rankine cycle with regeneration

With the increase in T1, cycle efficiency increased by $12.73 \%$. On the other hand, the pressure ratio, despite being in the order of 0.0095 , that is, the pumps consume only $0.95 \%$ of the work produced by the turbine, it decreased to $0.61 \%$ in relation to the extreme values of the range used for the temperature and pressure P2 of 0.5 $\mathrm{MPa}$. By bleeding the steam from the turbine at higher pressure P2, the efficiency increases, but so does the working ratio. This indicates that there is a point at which the increase in the pressure ratio is such that the efficiency begins to decrease.

\section{CASE STUDY 3: The ideal Rankine cycle with cogeneration}

The influence of the amount of steam extracted in the pipe between the boiler and the turbine and through the turbine for the process heater (steam extraction at 4 and 5 respectively) on the utilization factor $\left(e_{u}\right)$ and the process waste heat $(Q L)$ was studied. For this purpose, the steam was extracted from 4 and 5 maintaining the principle of quantity of mass. The initial process data is shown in Table 3.

TABLE III. Initial conditions for case study 3

\begin{tabular}{|c|c|c|c|c|c|}
\hline T1 $\left({ }^{\circ} \mathbf{C}\right)$ & P1 (MPa) & P5 (MPa) & P6 (MPa) & Extraction of vap. 4 (\%) & Extraction of vap. 5 $(\%)$ \\
\hline 550 & 7 & 1 & 0.01 & 5 & 50 \\
\hline
\end{tabular}


TABLE IV. Initial conditions for case study 3(continued)

\begin{tabular}{|c|c|c|}
\hline mass flow $(\mathrm{kg} / \mathrm{s})$ & $\eta$ turbine (\%) & 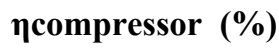 \\
\hline 15 & 100 & 100 \\
\hline
\end{tabular}

$e_{u}$ and $Q L$ were calculated by varying the amount of steam extracted before the turbine (4) over a range of 5 to 40 $\%$ of the mass flow, and 50,55 and $60 \%$ of the mass flow when it was circulating through the turbine. The results are shown in Figure 8.

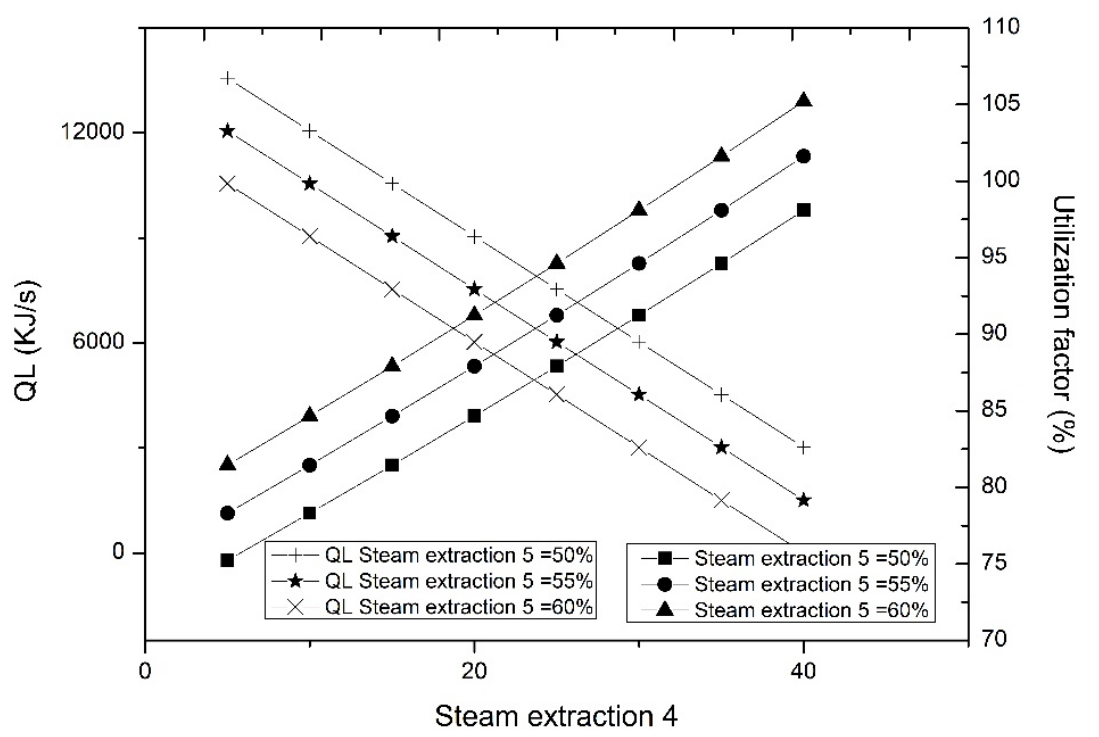

Fig. 8. Results of the case study of the ideal Rankine cycle with cogeneration

This case study shows the obviousness of the cycle. The more mass that is used for other processes, the cycle utilization factor increases regardless of the amount of mass flow extracted at each point. Although the remaining fraction of the mass flow allowed to expand in the turbine does work and this is related proportionally to the utilization factor, whenever there is a flow through the turbine waste heat will be generated, which decreases the utilization factor of the cycle. Therefore, a cycle with a utilization factor of $100 \%$ will have zero waste heat.

\section{CONCLUSIONS}

The implementation of the Powercycle ${ }^{\circledR}$ software was validated in different case studies that allowed a critical and satisfactory analysis of the behavior of the power cycles studied in this article.

\section{REFERENCS}

[1] M. Ashouri et al., "Exergy and Exergo-economic analysis and optimization of a solar double pressure organic Rankine cycle," Therm. Sci. Eng. Prog., 2017.

[2] Z. Yi et al., "Thermo-economic-environmental optimization of a liquid separation condensation-based organic Rankine cycle driven by waste heat," J. Clean. Prod., vol. 184, pp. 198-210, 2018.

[3] K. Braimakis and S. Karellas, "Exergetic optimization of double stage Organic Rankine Cycle (ORC)," Energy, vol. 149, pp. 296-313, 2018.

[4] H. Huang, J. Zhu, W. Deng, T. Ouyang, B. Yan, and X. Yang, "Influence of exhaust heat distribution on the performance of dual-loop organic Rankine Cycles (DORC) for engine waste heat recovery," Energy, 2018.

[5] G. Yu, G. Shu, H. Tian, Y. Huo, and W. Zhu, "Experimental investigations on a cascaded steam-/organic-Rankine-cycle (RC/ORC) system for waste heat recovery (WHR) from diesel engine,” Energy Convers. Manag., vol. 129, pp. 43-51, 2016.

[6] O. Bounefour and A. Ouadha, "Performance improvement of combined organic Rankine-vapor compression cycle using serial cascade evaporation in the organic cycle," Energy Procedia, vol. 139, pp. 248-253, 2017.

[7] F. Zhou, S. N. Joshi, R. Rhote-Vaney, and E. M. Dede, "A review and future application of Rankine Cycle to passenger vehicles for waste heat recovery,” Renew. Sustain. Energy Rev., vol. 75, pp. 1008-1021, Aug. 2017.

[8] M. Hofmann and G. Tsatsaronis, "Comparative exergoeconomic assessment of coal-fired power plants - Binary Rankine cycle versus conventional steam cycle," Energy, vol. 142, pp. 168-179, Jan. 2018.

[9] O. Aboelwafa, S.-E. K. Fateen, A. Soliman, and I. M. Ismail, "A review on solar Rankine cycles: Working fluids, applications, and cycle modifications,” Renew. Sustain. Energy Rev., vol. 82, pp. 868-885, Feb. 2018.

[10] S. Anvari, H. Taghavifar, and A. Parvishi, "Thermo- economical consideration of Regenerative organic Rankine cycle coupling with the absorption chiller systems incorporated in the trigeneration system," Energy Convers. Manag., vol. 148, pp. 317-329, Sep. 2017.

[11] H. Zebian and A. Mitsos, “A double-pinch criterion for regenerative Rankine cycles,” Energy, vol. 40, no. 1, pp. 258-270, Apr. 2012. 
[12] C. Fu, R. Anantharaman, and T. Gundersen, "Optimal integration of compression heat with regenerative steam Rankine cycles in oxycombustion coal based power plants," Energy, vol. 84, pp. 612-622, May 2015.

[13] J.-A. R. Sarr and F. Mathieu-Potvin, "Increasing thermal efficiency of Rankine cycles by using refrigeration cycles: A theoretical analysis," Energy Convers. Manag., vol. 121, pp. 358-379, Aug. 2016.

[14] N. M. Isa, C. W. Tan, and A. H. M. Yatim, "A comprehensive review of cogeneration system in a microgrid: A perspective from architecture and operating system,” Renew. Sustain. Energy Rev., vol. 81, pp. 2236-2263, Jan. 2018.

[15] L. Zhang, M. Chennells, and X. Xia, "A power dispatch model for a ferrochrome plant heat recovery cogeneration system," Appl. Energy, Aug. 2017.

[16] A. Escorcia, A. Avila and G. Valencia,"Design and implementation of a virtual laboratory on the sicvi platform for the thermodynamics chair of the atlantic university". Final career proyect, Faculty of Engineering, Universidad del Atlántico, Atlántico, Colombia, 2016.

\section{AUTHOR PROFILE}

Guillermo Eliecer Valencia Ochoa born in Barranquilla, Colombia on. Is a full-time professor at the Universidad del Atlántico. Received a degree in Mechanical Engineering from Universidad del Norte, located in Barranquilla, Colombia in 2005. Master in Mechanical Engineering from Universidad del Norte, Barranquilla, Colombia in 2008. Ph. D in Engineering from the Universidad Pontificia Bolivariana, Medellin, Colombia in 2014. He is an assistant professor of the Mechanical Engineering Program, Specialization in Energy Efficient Management and Master in Energy Management at Universidad del Atlántico.

Natalia Duarte Forero born in Barranquilla. He is a Student in Mechanical Engineering at Universidad del Atlantico. In his undergraduate thesis is working on energy management in thermal engine. St. Duarte is member of the engineering Researchstudent staff.

Donoban Arango Barrios born in Barranquilla. He is a Student in Mechanical Engineering at Universidad del Atlantico. In his undergraduate thesis is working on renewable energy in industrial process. St. Arango is member of the engineering Researchstudent staff. 